\title{
The Canadian Association of Gastroenterology Interactive Lecture Series: A virtual learning tool for the office and home
}

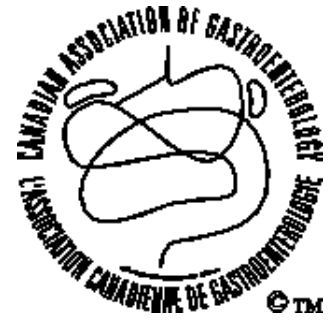

En français voir page 733

\author{
Richard N Fedorak $\mathrm{MD}^{1}$, Desmond J Leddin $\mathrm{MB}^{2}$ \\ ${ }^{1}$ Chair, CAG Lecture Series, ${ }^{2}$ Chair, CAG Education Committee
}

\section{WHAT IS THE CANADIAN ASSOCIATION OF GASTROENTEROLOGY (CAG) INTERACTIVE LECTURE SERIES?}

The CAG Interactive Lecture Series is celebrating its first anniversary this month, and is cosponsored by the CAG, Abbott Laboratories Ltd, Axcan Pharma Inc and Schering Canada Inc.

This online, CAG-directed, educational program is a highly innovative 'virtual' learning opportunity that allows you to visually review lectures, workshops and symposia sessions from the Canadian Digestive Diseases Week and other national and provincial educational events at your leisure.

The state-of-the-art lectures, symposia and workshops available on the CAG Interactive Lecture Series are chosen by the CAG to represent the broad spectrum of gastrointestinal clinical practice and to appeal to gastroenterologists, surgeons and general internists with a major interest in gastrointestinal disorders.

Educational presentations that occur across the country and throughout the year are constantly and carefully evaluated, and with the author's permission, digitally taped and remastered into an outstanding visual and audio presentation. You are able to listen to and watch these educational presentations wherever and whenever you like. Neither the content nor the context of the presentation is ever altered.

\section{HOW DO I ACCESS THE CAG INTERACTIVE LECTURE SERIES?}

The CAG would like to remind you that the subscription to the CAG Interactive Lecture Series is free!
To subscribe to the CAG Interactive Lecture Series you must obtain an introduction CD-ROM. This CD-ROM acts like a key and permits you to access each of the educational presentations as they become available online, which occurs on a weekly basis. The CD-ROM also permits you to download new presentations as they become available and acts as a storage facility for accumulating lectures for future or repeat viewing.

The CD-ROM is available by e-mailing your request to $<$ contact@cdpharma.com > or by contacting your local representative from one of the cosponsors: Abbott Laboratories Ltd, Montreal; Axcan Pharma Inc, Mont St-Hilaire; and Schering Canada Inc, Pointe-Claire.

Please be sure to check the CAG Web site at $<$ http://www.cag-acg.org/sponsors/education.htm> for a complete list of all available presentations and regularly for any new online presentations that may have been added to the program. There are now more than $30 \mathrm{~h}$ worth of worldclass presentations from over 90 separate lectures available through this exciting program and more are being added weekly (Table 1).

\section{WHAT DO I GAIN FROM THE CAG INTERACTIVE LECTURE SERIES?}

The CAG Interactive Lecture Series is ideal for the busy practitioner who cannot always attend a live educational event. The CAG selects presentations that occur at a multitude of venues across Canada, making it easy for the physician to feel comfortable that he/she is not missing important information. Presentations selected must be particularly relevant and timely in the area of management or therapeutics of gastrointestinal disorders.

Abbott Laboratories Ltd.

The CAG is proud to acknowledge its Benefactor Corporate Sponsors:

AstraZeneca Canada Inc.

Axcan Pharma Inc.

Janssen-Ortho Inc. 
Accessing the presentations on your own time and leisure, and using them to answer questions generated in your day-to-day practice permits the CAG Interactive Lecture Series to be used to meet the Royal College of Physicians and Sugeons of Canada's requirements for Section 4 credits (1credit/h, no maximum).

You can use the CAG Interactive Lecture Series as a resource to obtain the latest information and updates on a particular area. For example, you may wish for an update on the latest developments in the use of antiviral therapy for viral hepatitis, immunomodulators for irritable bowel disease (IBD) or acid suppressors for dyspepsia. By scanning the presentations available on the CAG Interactive Lecture Series you will find the latest updates by worldrenowned experts in the field.

We encourage you to join the growing number of physicians who are using the CAG Interactive Lecture Series as an important tool in their daily learning and clinical practice.

TABLE 1

Presentations available through the Canadian Association of Gastroenterology (CAG) Interactive Lecture Series

Presentation

number

2

3

4

5

6

CAG Interactive Lecture Series presentation title

Existing Evidence on the Safety of Long Term PPI

VIIth World Congress of the International Society for Diseases of the Esophagus

Should PPI Be Used Chronically or on Demand?

VIIth World Congress of the International Society for Diseases of the Esophagus

Inducing Remission in Ulcerative Colitis

Trends in Inflammatory Bowel Disease Therapy 1999 - An Official Satellite Symposium of GASTRO'99

Remission Maintenance in Ulcerative Colitis

Trends in Inflammatory Bowel Disease Therapy 1999 - An Official Satellite Symposium of GASTRO'99

Induction Therapy in Crohn's Disease

Trends in Inflammatory Bowel Disease Therapy 1999 - An Official Satellite Symposium of GASTRO'99

Maintenance of Remission in Crohn's Disease: Efficacy of Drug Therapy

Trends in Inflammatory Bowel Disease Therapy 1999 - An Official Satellite Symposium of GASTRO'99

Medical Management of Proctosigmoiditis and Hemorrhoids

Trends in Inflammatory Bowel Disease Therapy 1999 - An Official Satellite Symposium of GASTRO '99

Myths and Facts in the Role of Endoscopy, pH Monitoring and Other Forms of Investigation in GERD

Canadian Digestive Diseases Week - Highlights From the 5th Annual Meeting

Myths and Facts in the Management of Patients With No Endoscopy, or With Negative

Endoscopy or With Mild Esophagitis

Canadian Digestive Diseases Week - Highlights From the 5th Annual Meeting

Myths and Facts in the Principles of Long-Term Treatment of Patients With Severe Esophagitis

Canadian Digestive Diseases Week - Highlights From the 5th Annual Meeting

Beneficial Effect of $H$ pylori Eradication Therapy on Long-Term Symptom Relief in

Primary Care Patients With Uninvestigated Dyspepsia: The CADET-Hp Study

Canadian Digestive Diseases Week - Highlights From the 5th Annual Meeting

Barrett's, $H$ pylori and GE Junction Cancer

Canadian Digestive Diseases Week - Highlights From the 5th Annual Meeting

The Esophagus: In Sickness and in Health

Canadian Digestive Diseases Week - Highlights From the 5th Annual Meeting
Presenter

Dr Richard Hunt

Dr Naoki Chiba

Dr Stephen B Hanauer

Dr Jurgen Schölmerich

Dr A Hillary Steinhart

Dr Paul Rutgeerts

Prof Massimo Campieri

Dr André Duranceau

Dr Richard PE Reynolds

Dr Wilfred M Weinstein

Dr Naoki Chiba

Dr Wilfred M Weinstein

Dr William Paterson 
TABLE 1 (continued)

Presentations available through the Canadian Association of Gastroenterology (CAG) Interactive Lecture Series

Presentation
number

14

15

16

17

18

19

20
CAG Interactive Lecture Series presentation title

Pathogenesis and Prevention of Colon Cancer

Canadian Digestive Diseases Week - Highlights From the 5th Annual Meeting

From the Farm to Big Pharma: The Development of Hepatitis B Antiviral Therapy

Canadian Digestive Diseases Week - Highlights From the 5th Annual Meeting

RCPSC Maintenance of Certification

Canadian Digestive Diseases Week - Highlights From the 5th Annual Meeting

The Efficacy of Biological Therapy in IBD

Canadian Digestive Diseases Week - Highlights From the 5th Annual Meeting

New Approaches to Steroid Dependent \& Refractory Crohn's Disease

New Paradigms in the Management of Crohn's Disease

Current Management Strategies for Fistulous Crohn's Disease

New Paradigms in the Management of Crohn's Disease

Efficacy \& Safety of Biologics

New Paradigms in the Management of Crohn's Disease

Cytokines in Inflammatory Bowel Disease: Role in Pathophysiology, Diagnostics and Therapy

ULIBD 2001: Update on Liver \& Inflammatory Bowel Diseases

Genomics and Proteomics

ULIBD 2001: Update on Liver \& Inflammatory Bowel Diseases

Pathogenesis of Chronic Inflammation

ULIBD 2001: Update on Liver \& Inflammatory Bowel Diseases

Use of PPI Acid Suppression as a Diagnostic Test in the Management of GERD and Dyspepsia

Canadian Digestive Diseases Week: Highlights from the 6th Annual Meeting

Top 4 Basic Science Abstracts From Presidential Plenary/Poster Sessions

10th Annual Digestive Disease Week Review Course

Clinical Abstracts: Presidential Plenary Sessions

10th Annual Digestive Disease Week Review Course

Cancer and Cancer Screening

10th Annual Digestive Disease Week Review Course

Hepatobiliary/Non-Viral (Including ASLD)

10th Annual Digestive Disease Week Review Course

Hepatobiliary/Viral (Including ASLD)

10th Annual Digestive Disease Week Review Course

Advanced Therapeutic Endoscopy

10th Annual Digestive Disease Week Review Course

Extra-Esophageal Manifestations of GERD

10th Annual Digestive Disease Week Review Course

Ulcerative Colitis

10th Annual Digestive Disease Week Review Course

Crohn's Disease

10th Annual Digestive Disease Week Review Course

Gastroesophageal Reflux Disease
Dr Jack R Wands

Dr Valeer J Desmet

Presenter

Dr Raymond DuBois

Dr Lorne Tyrrell

Dr John WD McDonald

Dr Stephan Targan

Dr Gary Lichtenstein

Dr Remo Panaccione

Dr Sander van Deventer

Dr Stefan Schreiber

Dr Raymond Lahaie

Dr D Grant Gall

Dr Robert Hilsden

Dr Ron Bridges

Dr Vince G Bain

Dr Mark G Swain

Dr Gary R May

Dr Connie M Switzer

Dr Bruce Yacyshyn

Dr Remo Panaccione

Dr Philip Blustein

continued on next page 
TABLE 1 (continued)

Presentations available through the Canadian Association of Gastroenterology (CAG) Interactive Lecture Series

\section{Presentation}

number

35

36

37

38
CAG Interactive Lecture Series presentation title

Drug-Drug Interactions: The Role of the Cytochrome P-450 Enzyme System in the Metabolism of Proton Pump Inhibitors

Drug-Drug Interactions With Proton Pump Inhibitors: The Role of the Cytochrome P-450 Enzyme System in the Metabolism of Proton Pump Inhibitors

MRCP vs ERCP

CDDW 2002: Imaging and Endoscopy

CT-Colography (Virtual Colonoscopy) vs Colonoscopy

CDDW 2002: Imaging and Endoscopy

Peptic Ulcer Bleeding

CDDW 2002: Imaging and Endoscopy

Pharmacological Advances in the Treatment of Upper Gastrointestinal Bleeding

CDDW 2002: Imaging and Endoscopy

Advances in Noncardiac Chest Pain

Canadian Digestive Diseases Week 2002

Recent Studies on Esophageal Surgery

Canadian Digestive Diseases Week 2002

Extraesophageal Presentations of GERD

Canadian Digestive Diseases Week 2002

Introduction to Ambulatory Care in Canada

Canadian Digestive Diseases Week 2002

Politics of Independent Ambulatory Endoscopy - Regulatory Bodies: Where Is the Hold Up? Independent Ambulatory Endoscopy in Canada: Is the Time Ripe?

The Cost/Economics of Setting Up an Outpatient Endoscopy Clinic Independent Ambulatory Endoscopy in Canada: Is the Time Ripe?

Personal Experience in Running an Outpatient Ambulatory Care Endoscopy Unit Is it Worth It?

Independent Ambulatory Endoscopy in Canada: Is the Time Ripe?

Management of GI Bleeding

Bone Loss and IBD

ULIBD 2001: Update on Liver \& Inflammatory Bowel Diseases

Emerging Indications for Infliximab

ULIBD 2001: Update on Liver \& Inflammatory Bowel Diseases

Malignancy-Lymphoma in CD

ULIBD 2001: Update on Liver \& Inflammatory Bowel Diseases

The Role of Infliximab in the Treatment of CD: US Experience

ULIBD 2001: Update on Liver \& Inflammatory Bowel Diseases

Health Care Burden From HCV in North America: Projections for the Future

ULIBD 2001: Update on Liver \& Inflammatory Bowel Diseases

The Effect of Antiviral Therapy on Hepatic Fibrosis in Chronic Hepatitis C

ULIBD 2001: Update on Liver \& Inflammatory Bowel Diseases

Future Therapies in HCV

ULIBD 2001: Update on Liver \& Inflammatory Bowel Diseases

Fibre and Colon Cancer

Canadian Digestive Diseases Week - Highlights from the 6th Annual Meeting
Presenter

Dr Victor Plourde

Dr John R Horn

Dr Joseph Romagnuolo

Dr Benoit C Pineau

Dr Norman Marcon

Dr Alan N Barkun

Dr William Paterson

Dr André Duranceau

Dr Michel Boivin

Dr Flavio M Habal

Dr Michael I Gould

Don Montgomery

Dr Murray Fisher

Dr Daniel C Sadowski

Dr Gordon R Greenberg

Dr Elena Hitraya

Dr Roger B Cohen

Dr Stephen Hanauer

Dr Gary L Davis

Dr Thierry Poynard

Dr Willis C Maddrey

Dr Young-In Kim 
TABLE 1 (continued)

Presentations available through the Canadian Association of Gastroenterology (CAG) Interactive Lecture Series

\section{Presentation}

number

57

58

59

60

61

62

63

64

\section{CAG Interactive Lecture Series presentation title}

Long-Term Complications of TPN

Canadian Digestive Diseases Week - Highlights from the 6th Annual Meeting

Short Bowel Syndrome: Role of Trophic Factors in Intestinal Adaptation

Canadian Digestive Diseases Week - Highlights from the 6th Annual Meeting

Recent Advances in the Treatment of Hepatitis C

Canadian Digestive Diseases Week - Highlights from the 6th Annual Meeting

Diagnosis and Management of IBS: Meta-Analysis of IBS Pharmacotherapy

Canadian Digestive Diseases Week - Highlights from the 6th Annual Meeting

Functional GI Disorders: Points of View

Canadian Digestive Diseases Week - Highlights from the 6th Annual Meeting

The Gut Response to Stress: Implications for Functional GI Disorders

Canadian Digestive Diseases Week - Highlights from the 6th Annual Meeting

Should I Try to Convince my Hospital to Buy EUS?

Canadian Digestive Diseases Week - Highlights from the 6th Annual Meeting

Metal or Plastic Stents for Bile Duct Obstruction: What Is the Most Cost-Effective

Approach?

Canadian Digestive Diseases Week - Highlights from the 6th Annual Meeting

Utility of Serological Immune Markers in the Diagnosis, Differentiation and Stratification of IBD

Canadian Digestive Diseases Week - Highlights From the 6th Annual Meeting

Purine Metabolites in IBD: Therapeutic Use and Metabolic Testing

Canadian Digestive Diseases Week - Highlights From the 6th Annual Meeting

Treating Fistulizing Crohn's Disease

Canadian Digestive Diseases Week - Highlights From the 6th Annual Meeting

Probiotic and Antibiotic Therapy for IBD

Canadian Digestive Diseases Week - Highlights From the 6th Annual Meeting

Special Pediatric Management Issues in IBD

Canadian Digestive Diseases Week - Highlights From the 6th Annual Meeting

The Role of 5-ASA and Corticosteroids in Treating Crohn's Disease

2001: A GI and Liver Odyssey Program

Future Treatments in IBD: Where Do We Go From Here?

2001: A GI and Liver Odyssey Program

Cirrhose biliaire primitive et hypertension portale : la place de l'ursodiol

Nonalcoholic Steatohepatitis: An Expanding Clinical Entity

Update on the Treatment of NASH

Osteoporosis in IBD

Therapy With AZA/6-MP: The Role of Metabolite Monitoring and TPMT Pharmacogenetics

Maintenance Therapy in Inflammatory Bowel Disease: Focus on Mesalamine

The Truth About Probiotics in Inflammatory Bowel Disease

So How Does UDCA Play a Role in the Treatment of Cholestasis?

CDDW 2002: From Transporters to Viruses - New Mechanisms and Treatment for

Cholestasis

PBC and PSC: Infectious Diseases?

CDDW 2002: From Transporters to Viruses - New Mechanisms and Treatment for

Cholestasis
Presenter

Dr J Scott Whittaker

Dr James S Scolapio

Dr Jay H Hoofnagle

Dr John K Marshall

Dr W Grant Thompson

Dr Victor Plourde

Dr Anand Sahai

Dr Alan Barkun

Dr Marla Dubinsky

Dr William Sandborn

Dr Brian G Feagan

Dr Fergus Shanahan

Dr Ernest Seidman

Dr A Hillary Steinhart

Dr Kenneth Croitoru

Dr Pierre-Michel Huet

Dr David Brandhagen

Dr Keith Lindor

Dr Kerry Siminoski

Dr Ernest Seidman

Dr Malcolm Champion

Dr Richard Fedorak

Dr Ulrich Beuers

Dr James M Neuberger

continued on next page 
TABLE 1 (continued)

Presentations available through the Canadian Association of Gastroenterology (CAG) Interactive Lecture Series

\begin{tabular}{|c|c|c|}
\hline $\begin{array}{l}\text { Presentation } \\
\text { number }\end{array}$ & CAG Interactive Lecture Series presentation title & Presenter \\
\hline \multirow[t]{2}{*}{81} & What Governs Normal Bile Flow? & Dr Alan Hofmann \\
\hline & $\begin{array}{l}\text { CDDW 2002: From Transporters to Viruses - New Mechanisms and Treatment for } \\
\text { Cholestasis }\end{array}$ & \\
\hline \multirow[t]{2}{*}{82} & Genetic Mutations Causing Cholestasis in Children and Adults & Dr Rick Schreiber \\
\hline & $\begin{array}{l}\text { CDDW 2002: From Transporters to Viruses - New Mechanisms and Treatment for } \\
\text { Cholestasis }\end{array}$ & \\
\hline \multirow[t]{2}{*}{83} & Current Therapy for Chronic Hepatitis C & Dr S Victor Feinman \\
\hline & Hepatology Update 2002 & \\
\hline \multirow[t]{2}{*}{84} & Treatment of Chronic Hepatitis B & Dr Morris Sherman \\
\hline & Hepatology Update 2002 & \\
\hline \multirow[t]{2}{*}{85} & Endoscopy and Biopsy Issues: Why, When, Where? & Dr Wilfred M Weinstein \\
\hline & Diagnostic and Therapeutic Approaches in GI and Liver Disease & \\
\hline \multirow[t]{2}{*}{86} & Diagnosis of Suspected Small Bowel Bleeding & Dr Dennis Jensen \\
\hline & Diagnostic and Therapeutic Approaches in GI and Liver Disease & \\
\hline \multirow[t]{2}{*}{87} & $\begin{array}{l}\text { Canadian Association of Gastroenterology Clinical Practice Guidelines: } \\
\text { The Use of Infliximab in Crohn's Disease }\end{array}$ & Dr Remo Panaccione \\
\hline & Update on Liver and Inflammatory Bowel Diseases 2002 & \\
\hline \multirow[t]{2}{*}{88} & $\begin{array}{l}\text { A Crohn's Disease Clinical Trial Evaluating Infliximab in a New Long-Term } \\
\text { Treatment Regimen (ACCENT 1) }\end{array}$ & Dr Richard Fedorak \\
\hline & Update on Liver and Inflammatory Bowel Diseases 2002 & \\
\hline \multirow[t]{2}{*}{89} & Clinical Trials With Infliximab: Implications for Practice & Dr Stephen Hanauer \\
\hline & Update on Liver and Inflammatory Bowel Diseases 2002 & \\
\hline \multirow[t]{2}{*}{90} & Optimizing Long-Term Treatment Algorithms in Crohn's Disease & Dr Stephen B Hanauer \\
\hline & Disease Modification in IBD: Exploring Current Clinical Opportunities - Symposium & \\
\hline \multirow[t]{2}{*}{91} & $\begin{array}{l}\text { Debate: Infliximab Is a Preferable Treatment to Corticosteroids for Induction of Remission } \\
\text { in Patients With Active Crohn's Disease - PRO }\end{array}$ & Dr Daniel H Present \\
\hline & Update on Liver and Inflammatory Bowel Diseases 2002 & \\
\hline \multirow[t]{2}{*}{92} & $\begin{array}{l}\text { Debate: Infliximab Is a Preferable Treatment to Corticosteroids for Induction of Remission } \\
\text { in Patients With Active Crohn's Disease - CON }\end{array}$ & Dr William J Sandborn \\
\hline & Update on Liver and Inflammatory Bowel Diseases 2002 & \\
\hline 93 & Are Glucocorticosteroids Obsolete in IBD? & Dr Paul J Rutgeerts \\
\hline \multirow[t]{2}{*}{94} & Disease Modification in IBD: Improving Treatment Outcomes & Dr Paul J Rutgeerts \\
\hline & Disease Modification in IBD: Exploring Current Clinical Opportunities - Symposium & \\
\hline \multirow[t]{2}{*}{95} & Fistulizing Crohn's Disease: Evolving Clinical Expectations & Dr Bruce E Sands \\
\hline & Disease Modification in IBD: Exploring Current Clinical Opportunities - Symposium & \\
\hline
\end{tabular}

ASA Acetysalicylic acid; AZA/6-MP Azathoprine/6-Mercaptopurine; CD Crohns disease; CT Computed tomography; ERCP Endoscopic retrograde cholangiopancreatography; EUS Endoscopic ultrasound; GE Gastroesophageal; GERD Gastroesophageal reflux disease; GI Gastrointestinal; HCV Hepatitis C virus; IBD Inflammatory bowel disease; IBS Irritable bowel syndrome; MRCP Magnetic resonance cholangiopancreatography; NASH Nonalcoholic steatohepatitis; PBC Primary biliary cirrhosis; PPI Proton pump inhibitors; PSC Primary sclerosing cholangitis; TPMT Thiopurine methyltransferase; TPN Total parenteral nutrition; UDCA Ursodeoxycholic acid; ULIBD Update on liver and inflammatory bowel diseases; US United States 


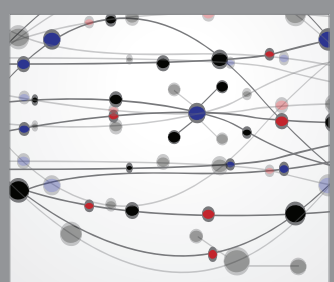

The Scientific World Journal
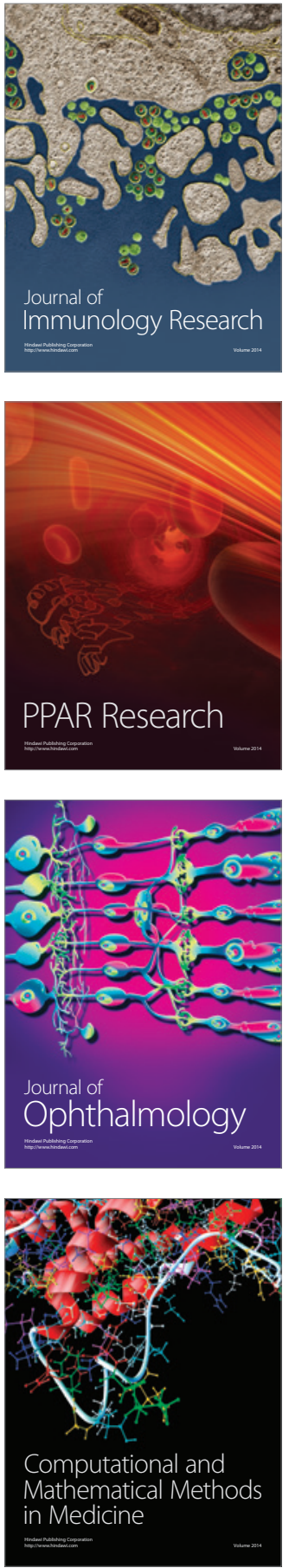

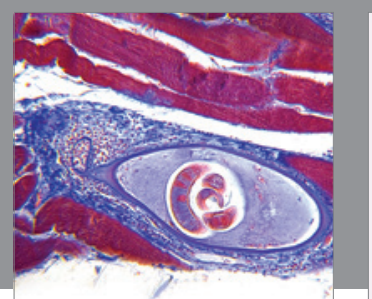

Gastroenterology Research and Practice

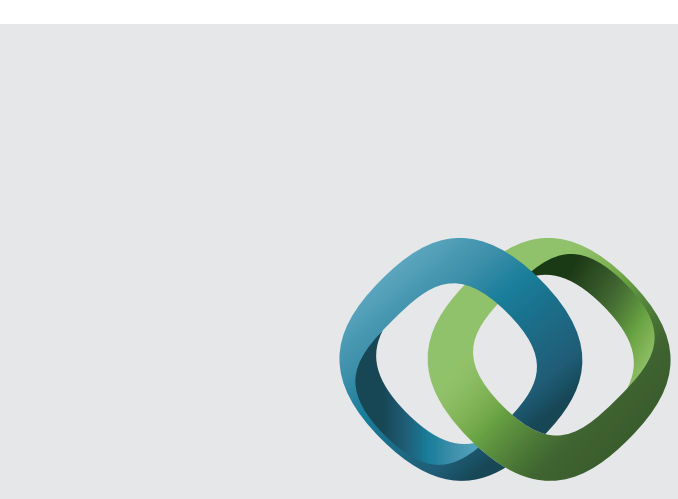

\section{Hindawi}

Submit your manuscripts at

http://www.hindawi.com
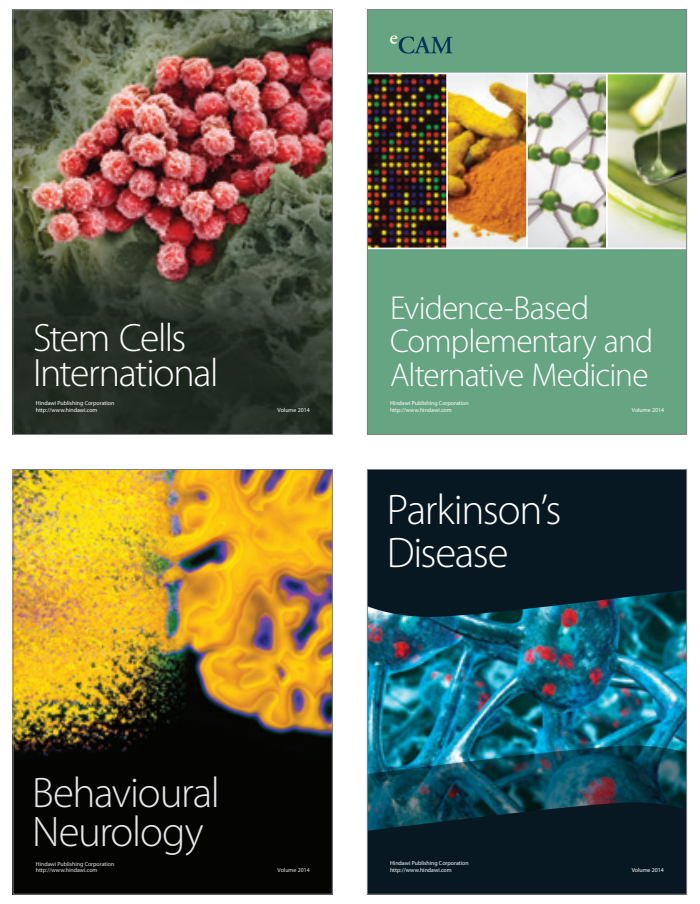
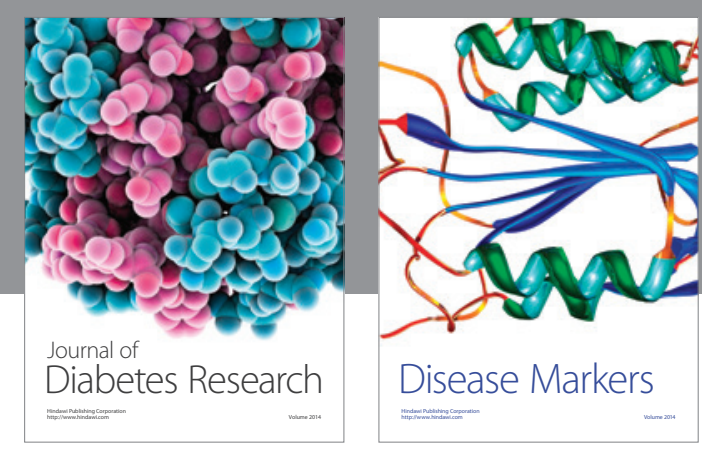

Disease Markers
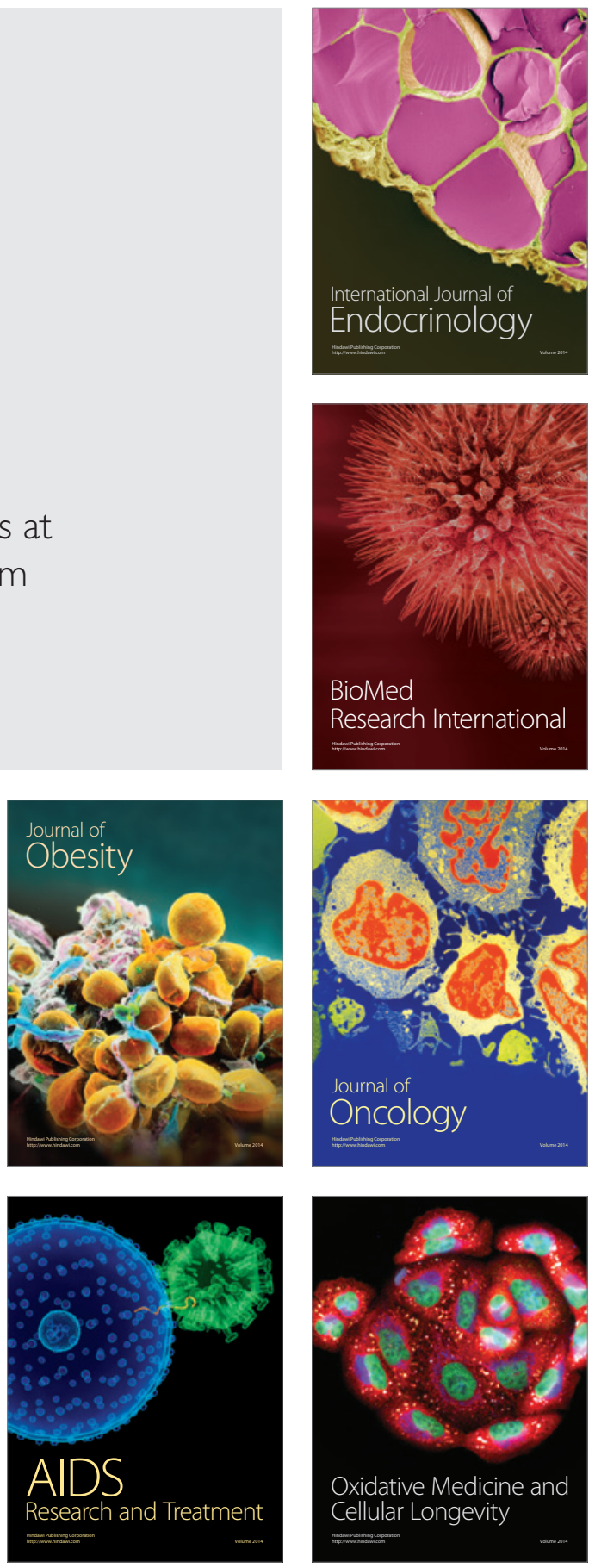